Article

\title{
Creating a Sustainable Workplace Environment: Influence of Workplace Safety Climate on Chinese Healthcare Employees' Presenteeism from the Perspective of Affect and Cognition
}

\author{
Beini Liu and Qiang Lu * \\ School of Business, Beijing Technology and Business University, Beijing 100048, China; liubeini818@126.com \\ * Correspondence: luqiang@btbu.edu.cn
}

Received: 30 January 2020; Accepted: 13 March 2020; Published: 19 March 2020

\begin{abstract}
Based on the stimulus-organism-response theory and cognitive-affective personality system theory, this paper explores how the theoretical model of the workplace safety climate (WSC) influences presenteeism. Affect-based trust and cognition-based trust are assessed, and the situational role of organization formalization is examined. Using a time-lagged research design, data from 396 healthcare employees were gathered and multiple regression and bootstrapping were used to test each hypothesis. The results show that: (1) WSC significantly reduces presenteeism. (2) Both affect-based trust and cognition-based trust mediate the relationship between WSC and presenteeism. Affect-based trust exerts a complete mediating role, while cognition-based trust exerts a partial mediating role. (3) Cognition-based trust completely mediates the relationship between affect-based trust and presenteeism. (4) Organization formalization exerts a positive moderating effect on the relationship between WSC and affect-based trust. However, it exerts no significant moderating effect on the relationship between WSC and cognition-based trust. This study overcame the single research perspective. Combined with organizational, work-related, and person-related factors, the internal logic of the impact of WSC on the decision-making process in presenteeism was identified. The research results provide practical information for enterprises to create a sustainable organizational environment, reduce risks related to human resources, and effectively manage organizational health.
\end{abstract}

Keywords: workplace safety climate; affect-based trust; cognition-based trust; organization formalization; presenteeism

\section{Introduction}

In the field of organizational management, presenteeism refers to the attending of work while ill, or succinctly put, "unhealthy and present" [1-4]. Due to the limitations that diseases, pains, and medical conditions impose, thus-affected employees operate within a gray area between full participation in work and absence from work [5]. It has been suggested that presenteeism may cause more productivity loss to an organization than absence [6,7].

Effective management of presenteeism helps to reduce the risks related to human resources management, thus imposing a positive impact on the success of the business [8]. Considering the positive correlation between high-performance work practices and company performance, some scholars have proposed that, in order to improve the success of an organization, human resources management practices need to manage presenteeism more systematically [9]. Since the effective management of presenteeism can improve organizational efficiency and thus become one of the important sources of organizational competitive advantage, this phenomenon has gained extensive 
attention from academic scholars and practitioners in organizational health and human resources management [1].

Presenteeism has become a common phenomenon in developed Western societies [10,11]. Caused by the cultural requirements to work hard and show perseverance, compared with Western employees, Chinese employees are more likely to work despite being ill [12,13]. Previous studies on presenteeism confirmed that job insecurity affects both the work behaviors and decisions of employees [3,5]. However, few studies have explored variables that were less proximal to the workplace such as environmental factors [1]. Sustainable psychology emphasizes the importance of creating a sustainable organizational environment that promotes employee health and well-being [14]. Workplace safety climate (WSC) is a typical safety-related organizational environment that positively correlated with safety outcomes [15]. The safety climate literature has examined the link between WSC and safety outcomes such as improve safety motivation, compliance with safe working behaviors, reduce injuries and accidents, promote safety performance $[16,17]$. According to previous study, the definition of WSC refers to safety management priorities, systems, practices, and procedures to reward, support, and persuade employees to behave safely in the present study [18]. This study aims to explore the internal mechanisms between WSC and presenteeism.

Stimulus-organism-response (SOR) theory points out that external environmental factors will stimulate the psychological state of an organism, thus affecting individual behavioral responses [19]. SOR theory provides a suitable theoretical framework for exploring the internal mechanisms underlying WSC and presenteeism. The organizational environment will stimulate employees to assume different psychological states and thus present different behavioral responses. As an organizational environment, WSC will stimulate employees to assume psychological states that are internalized in both affect and cognition [20], thus affecting presenteeism. Because presenteeism poses potential health risks, internalized psychological states need to address such risks. Trust is the confident and positive prediction of the goodwill and reliability of employees regarding the behavior of others or their organization under the circumstance of causing risks [21]. This definition provides the possibility to crack the "black box" between WSC and presenteeism. Therefore, this study combines the perspective of the cognitive-affective personality system (CAPS) and explores the intrinsic mechanism of presenteeism decision-making from the following two paths: affect-based trust and cognition-based trust [22].

The effectiveness of administrative control is highly dependent on the organizational structure [23]. Whether the safety-management-related administrative control contained in WSC can form shared perception among employees and be effectively implemented is closely related to the organizational structure. Organizational structures are important triggers to stimulate individual "cognitive-affective units" [24]. Scholars have called for an investigation of presenteeism to identify the process of decision-making by combining organizational, work-related, and person-related factors [1]. To address this call, this study introduces the organizational structure of organization formalization and explores the boundary conditions for the effectiveness of WSC.

To sum up, the present study expanded the existing knowledge from the following aspects. First, few previous studies have explored variables that were less proximal to the workplace, such as environmental factors [1]. This research aims to respond to the research appeal. Based on the SOR theory and the perspective of the CAPS theory, this study constructs a theoretical model in which WSC influences presenteeism through affect-based trust and cognition-based trust. By selecting WSC as a typical workplace environment factor, the present study enriches the research results of antecedents of presenteeism to some extent. Second, by introducing organizational structure, we have extended current understanding of boundary conditions under which WSC can be more effective or not. The present study integrated organizational, work-related, and person-related factors into a research framework, thus responding to the research appeal of previous scholars [1] and providing a more comprehensive view of the presenteeism decision-making process. Third, previous research on antecedents of presenteeism remains theoretical-, framework-, or literature-meta-analysis-based $[2,3,5,25,26]$. The present study enriches the empirical research in this field with a specific focus on the Chinese context. The research 
results help organizations to achieve a deeper understanding of presenteeism, promote the creation of a sustainable working environment, reduce risks related to human resources, and provide information for health promotion management.

\section{Literature Review and Hypotheses}

\subsection{Presenteeism and Theory Perspective}

With regard to the definition of presenteeism, existing research mainly utilizes two perspectives: "consequence perspective" and "behavioral perspective." The "consequence perspective" is dominated by North American scholars and focuses on the behavioral results induced by presenteeism. This perspective defines presenteeism as productivity loss and further economic loss due to health problems $[27,28]$. The "behavioral perspective" is dominated by European scholars and focuses on the behavior of presenteeism, defining presenteeism as the behavior of attending work despite feeling ill [2,4]. Scholars have proposed that this concept should focus more on the presenteeism behavior, rather than including behavioral motivation and results [3]. On the one hand, presenteeism includes both approach and avoidance motives [13], thus making it difficult to determine the specific motivation of employees. On the other hand, simply describing the results of presenteeism as a loss of productivity may ignore its increase in productivity compared with absence from work [3]. Therefore, this study adopted the general definition of presenteeism, i.e., showing up for work while ill. This definition has been accepted by most organization and management scholars and has been widely applied in subsequent studies $[11,13,29]$.

Most initial research on presenteeism focused on public health and the occupational medicine field. Scholars generally applied the recovery theory to explain the spiral loss phenomenon of "poor health-presenteeism-deterioration of health" [30]. With the attention of scholars in the field of organizational management, the "Job Demand-Resource" theory has been widely applied to the process of exploring the "impairment" and "incentive" caused by presenteeism to the individual [5,31]. Although the theory of "Job Demand-Resource" can explain how presenteeism affects employees as a form of work pressure, it does not have the social cognitive thrust needed to explain the "why and how" in the presenteeism context. Therefore, based on the transactional theory of stress, scholars have explored that self-efficacy and neuroticism were significantly associated with approach and avoidance motives for the act of presenteeism [13]. Based on social cognitive theory and combined with individual cognitive processes, scholars suggested that self-efficacy, outcome expectations, and goals of work involvement play an important role in explaining presenteeism [26].

Despite the lack of a direct empirical study on the mechanism of WSC and presenteeism, research has focused on a supportive working environment. Based on social information processing theory and resource conservation theory, it has been proposed that role ambiguity would increase presenteeism productivity loss, while supervisor support would decrease such a loss by reducing employee role ambiguity [32]. Based on the theory of social exchange, the buffering effect of perceived human resource management practices on presenteeism has been explored and the mediating effect of turnover intention has been described [33].

Although previous studies tried to explain presenteeism via various theories, the role of situational factors for stimulating different psychological states has been neglected. There is no simple contractual cognitive exchange between employees and organizations and the process of interaction is often mixed with complex affective factors [19]. The existing research only starts from the single perspective of social cognition [26] or social exchange [33], which may not be able to provide a comprehensive explanation on presenteeism. According to SOR theory and CAPS, if "WSC-presenteeism" is understood as a type of "stimulus-response" relationship, then affect-based trust and cognition-based trust are the cognitive and identification processes of this relationship. 


\subsection{Workplace Safety Climate and Presenteeism}

WSC emphasizes that organizations should establish safety management priorities, systems, practices, and procedures to reward, support, and persuade employees to behave safely [15]. Based on SOR theory, external environmental stimuli affect behavioral responses. Previous studies confirmed that active WSC significantly affects safety behaviors and positively improves safety performance $[16,17]$. Specifically, a positive safety climate is generated in the workplace, which can encourage employees to observe safe work practices and participate in activities related to safety [18]. The organization will improve WSC by formulating safety policies, requiring employees to abide by safety rules, and providing safety training. Thus, the organization has a significant positive impact on safety behavior [34]. The safety culture and shared safety awareness imposed by an organization will play a role in restricting and standardizing behaviors, promote safety compliance and safety participation behaviors, and thus further improve the safety performance of the organization [35].

Previous studies verified the significant impact of WSC on safety behaviors and safety performance. From the perspective of safety behaviors, under high WSC, an organization creates a safety culture, takes safety management measures, and emphasizes safety practices. This will reduce safety-damaging behaviors at work and continuously maintain personal health [36]. Presenteeism, as an act of working with illness, will cause certain losses to the personal physical and mental health of employees and obstruct safe production. Therefore, we can conclude that WSC could reduce presenteeism. In addition, from the perspective of safety performance, under high WSC, the organization will convey to its employees that safety management and safety practices have priority over production objectives [37]. This will stimulate employees to reduce work behaviors that are detrimental to safety performance. However, presenteeism, as a behavior that will decrease employee productivity and increase accident rate, will damage the safety performance of the organization. Therefore, this study concludes that WSC could significantly reduce presenteeism. Thus, the following hypothesis is proposed:

Hypotheses 1 (H1). WSC exerts a significant positive effect on presenteeism.

\subsection{The Mediating Effect of Trust}

Based on the SOR theory, external situational factors trigger both cognitive and affective processes within individuals [19]. Because presenteeism poses potential risks to employee health, internalized psychological states need to address such risks. Trust has been defined as a confident and positive prediction of the goodwill and reliability of employees regarding the behavior of others or organizations under the circumstance of causing risks [21]. Therefore, trust provides the possibility to identify the relationship between WSC and presenteeism. Trust consists of both affect-based trust and cognition-based trust [22]. Affect-based trust originates from the development of emotional relationships. A deep and stable social relationship forms during the process of reciprocal social exchange [38]. Cognition-based trust depends on the reasonable and objective evaluation of the characteristics of others or organizations, including their capability and reliability [39].

From the perspective of affect-based trust, first, the organization conveys to the management concept that the organization cares about the health and safety of its employees by creating positive WSC [34]. This consensus will induce employees to form stable social relationships in the process of social exchange with the organization. Second, active WSC prioritizes employee safety and health over the production target [37]. In such a safety culture, employees feel that the organization respects and cares for their health and safety, thus promoting affect-based trust in the organization. Third, in an organizational environment with high WSC, organizations will inquire how to improve workplace safety and adopt the opinions of employees. This policy to promote employee participation will strengthen the provision of mutual communication and emotional support [40], thus enhancing the degree of affect-based trust.

From the perspective of cognition-based trust, first, organizing a high WSC will improve safety and stability, and will reduce the possibility of the threats to stability. Therefore, employees assume 
that the organization is reliable and will thus be more committed to protecting their health and safety. Second, organizations with high WSC will provide more procedures for employees to express their opinions about how to improve safety management. The level of safety participation can be increased [41]. This will improve employees' cognition-based trust of the organizational safety management capabilities. Third, the organization will create a safe working environment by formulating safety-related policies, systems, and regulations. These characteristics will increase the trust of employees and realize the instrumental value of guidance, help, and support from the organization [12], thus increasing cognition-based trust. Consequently, the following hypotheses are proposed:

Hypotheses 2a (H2a). WSC exerts a significant positive effect on affect-based trust.

Hypotheses $\mathbf{2} \mathbf{b} \mathbf{( H 2 b )}$. WSC exerts a significant positive effect on cognition-based trust.

Based on the SOR theory, WSC (as a workplace situational stimulus) triggers individual affective and cognitive psychological states, based on which external behavioral responses are produced [19]. From the perspective of affect-based trust, first, this form of trust indicates that employees assume that the organization will meet their needs and will fulfill its normative commitments [42]. When employees have poor health, the organization will support them so that they can rest at home, thus reducing presenteeism. Second, affect-based trust will stimulate employees' affinity and trust in the organization [38]. This type of psychological resource can reduce the loss of emotional and psychological resources, and ultimately relieve the work pressure. It can be inferred that presenteeism, as a typical stressor, can also be relieved. Third, due to the high affective trust, organizations and colleagues will try their best to assist ill employees in completing their work. Employees do not have to worry about being absent from work due to illness, fearing that this will result in a delayed work schedule. Such employees are also not worried that their positions might be replaced during their illness absence, thus reducing presenteeism.

From the perspective of cognition-based trust, first, active WSC promotes employees' awareness of the capability of their organization to apply good safety management, and enables employees to reduce uncertainty when considering future working environment [42]. Therefore, employees do not need to worry about the impact of work uncertainty because of their absence from work due to illness, thus reducing presenteeism. Second, in organizations with high WSC, employees share the consensus that safety and health have absolute priority [37]. Employees will reduce unsafe production behaviors, thus presenteeism will be reduced. Third, cognition-based trust can increase the practical value perception of the health and safety guidance, because of the help and support provided by the organization. In case of illness, employees can obtain timely functional help from both their organizations and colleagues. For example, the organization will adjust the flexibility of work to allow employees to work at home, and colleagues are more willing to provide supportive behaviors such as job sharing, thus reducing presenteeism. Thus, the following hypotheses are proposed:

Hypotheses 3a (H3a). Affect-based trust mediates the relationship between WSC and presenteeism.

Hypotheses $\mathbf{3 b} \mathbf{b} \mathbf{H} \mathbf{3} \mathbf{b})$. Cognition-based trust mediates the relationship between WSC and presenteeism.

\subsection{Moderating Effect of Organizational Formalization}

Based on the SOR theory, the psychological state of an organism depends on stimulation by external environmental factors. WSC is a typical external environmental factor related to work, while its effectiveness may be limited by organizational circumstances. Organizational characteristics are important triggers that stimulate individual cognitive-affective units [24]. As an important feature of an organization, the organizational structure shows the structural system that has formed in response to the relationship between the members of the organization [23]. Organizational formalization is an organizational characteristic, referring to the degree to which an organization uses clear rules and policies to clarify norms, processes, and decisions of its operation [43]. Formalized organizations generally formulate a large number of rules, regulations, policies, standardized work processes, and 
clear work instructions [44]. Organizational formalization becomes the boundary condition for WSC to promote employee trust.

From the perspective of affect-based trust, this form of trust is based on sensibility and highlights goodwill, empathy, and high-quality exchange relationships [22]. First, when an organization is highly formalized, official documents, regulations, and procedures all signal to employees that the organization is willing to help and support healthy behaviors. Therefore, this will improve the perception of goodwill toward health. Second, the organization will prioritize safety and health over production targets by formulating numbers of clear and explicit regulations. When employees are ill, these organizations will show strong empathy and will not act at the expense of their safety and health. This strengthens the relationship between WSC and affect-based trust. Third, when the degree of organization formalization is high, such an organization strives to construct stable and predictable safeguard measures to demonstrate its intention to focus on safety and health. Therefore, this organization will establish high-quality exchange relations with its employees, promote employees' positive expectations of the organization, and thus enhance the positive influence of WSC on affect-based trust.

From the perspective of cognition-based trust, this form of trust is based on rationality [39]. Employees make judgments about their trust level based on previously perceived organizational management capability and reliability [22]. First, when an organization is highly formalized, the channel of information communication is direct. The employees' understanding of the organization's emphasis on safety and health tends to be unified. The work safety management can let employees more easily feel the cognitive trust it conveys. Second, organization formalization helps to reduce both uncertainty and opportunistic behavior [45]. When employees are absent from work due to illness, they do not need to worry that the organization will dismiss them or that colleagues will seize their job opportunities. Third, through organization formalization, safety management can be continuously institutionalized and standardized. This will enhance the security management capability of the organization, improve its reliability, and enhance the positive relationship between WSC and cognition-based trust. Thus, the following hypothesis is proposed:

Hypotheses 4a (H4a). Organizational formalization exerts a positive moderating effect on the relationship between WSC and affect-based trust.

Hypotheses $\mathbf{4 b}(\mathbf{H} 4 \mathbf{b})$. Organizational formalization exerts a positive moderating effect on the relationship between WSC and cognition-based trust.

Figure 1 shows the theoretical model.

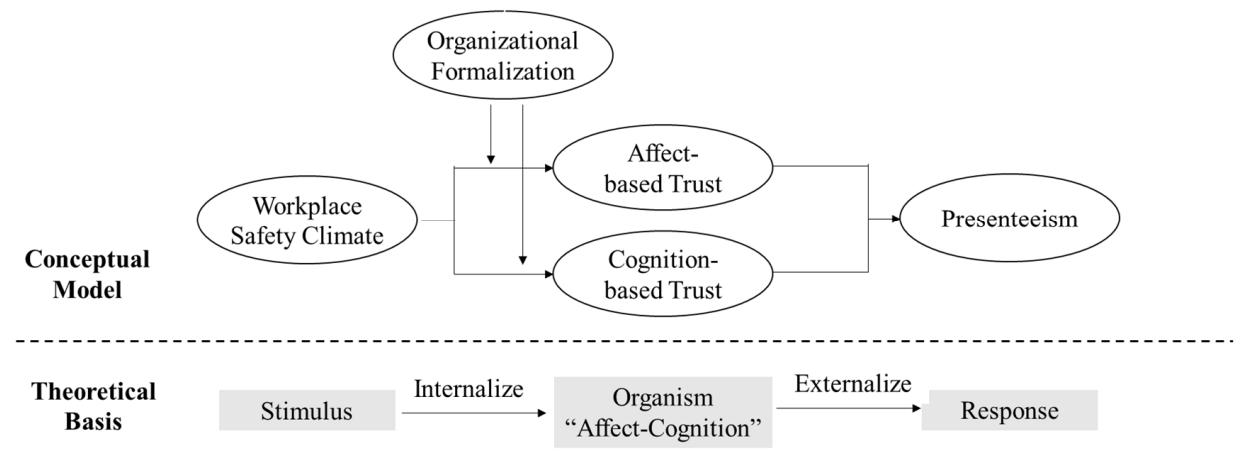

Figure 1. Conceptual model and theoretical basis.

\section{Methodology}

\subsection{Measures}

All the variables were taken or adapted from previously validated and published instruments. Because the scales were originally written in English under various study situations, they were refined 
and summarized appropriately according to the present study background and Chinese context, and then translated to Chinese by two independent researchers. This Chinese questionnaire was then subjected to a back-translation procedure by two independent researchers to ensure accuracy and consistency of the translation.

Independent variable. WSC was measured based on scales that were developed by Curcuruto et al. [17] and Neal and Griffin [18]. The four items of this measure reflect the extent of the importance and priority of the organization's relevant regulations, policies, and procedures for employee health and safety.

Mediating variable and moderation variable. Both the affect-based trust and cognition-based trust measurement scales were adopted from McAllister [22] and Colquitt et al. [42]. Affect-based trust reflects both the emotional investment and mutual feelings shared with the organization, and includes four items. Cognition-based trust reflects an objective evaluation of organizational capability, reliability, and stability, and specifically includes four items. The organizational formalization measurement scale was adopted from Pugh et al. [43] and Aryee et al. [44]. The four items of this measurement scale reflect the degree to which an organization uses explicit regulations and policies to clarify norms, processes, and decisions.

Dependent variable and control variable. The presenteeism measurement scale was mainly drawn from scales developed by Halbesleben et al. [2] and Aronsson et al. [4]. Both items of this measure reflect the frequency of the behavior of employees who persist in working despite being ill, evaluated over the past six months. Lu et al. (2013b) applied this scale to the Chinese context in the study [13]. In reference to the research results of previous scholars, gender, age, marriage, education, tenure, and employment type were used control variables [11,13,46].

\subsection{Sampling}

This study combined the time-lagged research design with the data screening method. The constructs measured at the same time will have artifactual covariation, leading to the expansion of correlation [47]. Time lags (one day to two months apart) help to reduce common method biases because they reduce the salience of the predictor variable or its accessibility in memory [48]. Therefore, this study used a time-lagged research design to collect data to reduce common method bias. The entire investigation lasted for 6 months, which is consistent with the recall cycle required by presenteeism measurement. Ethical review and approval was not required for the study on human participants in accordance with the local legislation and institutional requirements. Written informed consent from the participants was not required to participate in this study in accordance with the national legislation and the institutional requirements.

Questionnaires were distributed to healthcare employees from public healthcare institutions all over China. Due to the limitation of manpower and financial resources, this study selected three provinces or municipalities from the eastern, central and western regions respectively, including Beijing, Tianjin, Shandong, Jilin, Heilongjiang, Henan, Sichuan, and Guizhou. Then, 6 or 7 public healthcare institutions were randomly selected in each region for investigation, with a total of 53 institutions being selected. Each public healthcare institution distributed 12 questionnaires. In order to improve the representativeness of the samples, the 12 questionnaires included 6 frontline healthcare employees, 4 middle managers, and 2 senior managers. Data were collected across three data collection periods. During the first period for data collection, WSC, organizational formalization, health condition, and control variables were measured. A total of 636 questionnaires were distributed, 609 were collected, and 576 were identified as valid. In order to reduce cyclic causality, the following questionnaires were excluded from the data set: (1) Healthcare employees with no record of illness over the past year, because such a low record of illness indicates that these employees do not need to consider whether to work while ill. (2) Healthcare employees with a record of illness in the past year, because the record of illness indicates that these people become ill. According to these criteria, a total of 86 questionnaires were excluded, and 490 valid questionnaires entered the second round. The second period of data 
collection (three months later) measured both affect-based trust and cognition-based trust. A total of 490 questionnaires were distributed, 458 were collected, and 436 were valid. The last time of data collection happened three months later. A total of 436 questionnaires were distributed, 412 were collected, and 396 were valid. The final effective response rate was $62.3 \%$. In the sample of healthcare employees, $74.3 \%$ were females, had an average age of 38.25 years, $76.1 \%$ were married, $64.8 \%$ had a bachelor degree or below, an average tenure of 8.37 years, and $66.1 \%$ had permanent contracts.

\subsection{Nonresponse Bias and Common Method Bias Test}

Before conducting formal data analysis and hypothesis testing, nonresponse bias and common method bias were first examined. In this study, SPSS 22.0 and LISREL 8.80 were mainly used for data analysis and hypothesis testing. First, analysis of variance (ANOVA) was adopted to compare the mean differences between early and late respondents. This was done to test the nonresponse bias based on the control variables. The results showed no significant mean differences $(p>0.1)$, thus indicating that there was no problem of nonresponse bias in this study.

Second, common method bias is an artificial covariant between both predicted variables and valid standard variables, caused by the same data collection situation. Harman's single factor test is widely used by scholars because of its simplicity and ease of use [47]. Factor analysis of all items showed that all items could be loaded into five factors. The total explanation variation degree of these extracted five factors was $73.004 \%$, of which the first factor explanation variation degree was $23.824 \%$. No one factor explanation was identified for most variations, thus indicating that there is no severe common method bias problem in this study.

\section{Data Analysis and Results}

\subsection{Reliability and Validity}

As shown in Table 1, the Cronbach's $\alpha$ of each construct was found to exceed the cutoff value of 0.70 [49]. Composite reliability (CR) ranged from 0.842 to 0.984 , which exceed the recommended threshold of 0.7. All constructs in this study achieved good reliability.

Table 1. Measurement items and validity assessment.

\begin{tabular}{|c|c|c|c|c|}
\hline Constructs and Items & Std. Loading & Cronbach's $\alpha$ & CR & AVE \\
\hline Workplace Safety Climate (Neal and Griffin, 2006; Curcuruto et al., 2018) & & 0.886 & 0.922 & 0.747 \\
\hline OSC1: Management considers safety to be important & 0.879 & & & \\
\hline OSC2: Safety is given a high priority by management & 0.872 & & & \\
\hline OSC3: Uses any available information to improve existing safety rules & 0.905 & & & \\
\hline OSC4: Listens carefully to workers' ideas about improving safety & 0.797 & & & \\
\hline Affect-based Trust (McAllister, 1995; Colquitt et al., 2012) & & 0.812 & 0.842 & 0.572 \\
\hline AT1: I freely share health ideas and feelings in the organization. & 0.659 & & & \\
\hline AT2: I can talk freely about health difficulties I am having at work. & 0.808 & & & \\
\hline $\begin{array}{l}\text { AT3: My organization responds caringly when I share my } \\
\text { health problems. }\end{array}$ & 0.718 & & & \\
\hline AT4: I have invested a lot in the working relationship. & 0.829 & & & \\
\hline Cognition-based Trust (McAllister, 1995; Colquitt et al., 2012) & & 0.828 & 0.874 & 0.639 \\
\hline CT1: I trust my organization competence for the safety management. & 0.872 & & & \\
\hline CT2: I can rely on my organization not to make my job more difficult. & 0.905 & & & \\
\hline CT3: I trust and respect my organization. & 0.609 & & & \\
\hline CT4: I consider my organization to be reliability. & 0.779 & & & \\
\hline Presenteeism (Aronsson et al., 2000) & & 0.978 & 0.984 & 0.968 \\
\hline \multicolumn{5}{|l|}{ Have you experienced the following in the last 6 months? } \\
\hline PR1: Although you feel sick, you still force yourself to go to work. & 0.994 & & & \\
\hline $\begin{array}{l}\text { PR2: Although you have physical symptoms such as headache or } \\
\text { backache, you still force yourself to go to work. }\end{array}$ & 0.974 & & & \\
\hline Organizational Formalization (Pugh et al., 1968; Aryee et al., 2008) & & 0.869 & 0.901 & 0.696 \\
\hline OF1: Many safety management regulations and policies & 0.901 & & & \\
\hline OF2: Many practical safety rules and procedures guide & 0.824 & & & \\
\hline OF3: Enforce uniform security action standards & 0.877 & & & \\
\hline OF4: Regular formal safety training & 0.725 & & & \\
\hline
\end{tabular}


With regard to the validity test, first, all scales used in this study originated from mature studies, the validity of which has been proven by previous empirical studies, thus ensuring that the scale of this study achieved good content validity. As shown in Table 1, the average variance extracted (AVE) for constructs ranged from 0.572 to 0.968 . The AVE of each construct exceeded the variance attributable to its measurement error cutoff value of 0.50 . As shown in Table 2, the results of confirmatory factor analysis showed that the model had a good fit. This also showed that the scale achieved good convergent validity. Finally, as shown in Table 2, the square root of AVE of each variable exceeded the correlation coefficients between latent variables, which also indicates good discriminant validity of the scale.

Table 2. The correlation coefficient and the square root of AVE.

\begin{tabular}{|c|c|c|c|c|c|c|c|c|c|c|c|}
\hline Variable & 1 & 2 & 3 & 4 & 5 & 6 & 7 & 8 & 9 & 10 & 11 \\
\hline Gender & - & & & & & & & & & & \\
\hline Age & $-0.109 * *$ & - & & & & & & & & & \\
\hline Marriage & -0.036 & 0.476 ** & - & & & & & & & & \\
\hline Tenure & -0.004 & $0.667^{* *}$ & $0.584 * *$ & -0.059 & - & & & & & & \\
\hline Employment Type & 0.040 & $-0.426 * *$ & $-0.386^{* *}$ & $-0.155 * *$ & $-0.502 * *$ & - & & & & & \\
\hline $\begin{array}{c}\text { Workplace Safety } \\
\text { Climate }\end{array}$ & -0.018 & $0.169 * *$ & $0.088^{* *}$ & 0.033 & $0.128^{* *}$ & $-0.153 * *$ & 0.864 & & & & \\
\hline Presenteeism & 0.070 * & -0.049 & 0.051 & 0.090 ** & 0.023 & -0.038 & -0.057 & $-0.159 * *$ & $-0.063 *$ & 0.984 & \\
\hline \multirow[t]{2}{*}{$\begin{array}{l}\text { Organizational } \\
\text { Formalization }\end{array}$} & $0.098^{* *}$ & $-0.135^{* *}$ & -0.003 & 0.028 & -0.048 & 0.026 & -0.059 & $-0.252 * *$ & -0.253 ** & $0.185^{* *}$ & 0.834 \\
\hline & \multicolumn{11}{|c|}{$\chi 2=347.23, \mathrm{df}=192, \chi 2 / \mathrm{df}=1.808, \mathrm{RMSEA}=0.056, \mathrm{SRMR}=0.058, \mathrm{CFI}=0.98, \mathrm{IFI}=0.98, \mathrm{NFI}=0.95, \mathrm{GFI}=0.90$} \\
\hline
\end{tabular}

Note: ${ }^{*} p<0.05$; ${ }^{* *} p<0.01$; the diagonal numbers formatted in bold show the square root of AVE. RMSEA = root-mean-square error of approximation, $\mathrm{SRMR}=$ standard root mean-square residual, $\mathrm{CFI}=$ comparative fit index, $\mathrm{IFI}=$ incremental fit index, NFI = normed fit index, GFI = goodness-of-fit index.

\subsection{Hypotheses Testing}

To test the effects of the workplace safety climate on presenteeism and the mediating roles of both affect-based trust and cognition-based trust, this study constructed six regression models. The results of collinearity statistics showed that the tolerance of each model exceeded the cutoff value of 0.1 and the variance inflation factor (VIF) of each model was less than the cutoff value of 10 . These results suggest that the collinearity problem does not exist. Moreover, Table 3 shows that the Durbin-Watson statistic of each model is approximately 2 , indicating that the regression equation has no serial autocorrelation.

Table 3. Test results of the direct and mediating effects.

\begin{tabular}{|c|c|c|c|c|c|c|}
\hline \multirow[t]{2}{*}{ Variable } & Presenteeism & $\begin{array}{l}\text { Affect-Based } \\
\text { Trust }\end{array}$ & $\begin{array}{c}\text { Cognition-Based } \\
\text { Trust }\end{array}$ & Presenteeism & Presenteeism & Presenteeism \\
\hline & Model 1 & Model 2 & Model 3 & Model 4 & Model 5 & Model 6 \\
\hline Gender & $0.072 *$ & 0.016 & -0.018 & $0.075^{*}$ & $0.072 *$ & $0.079 *$ \\
\hline Age & $-0.110^{*}$ & $0.131 * *$ & $0.243^{* * *}$ & $-0.090^{*}$ & $-0.097^{*}$ & $-0.106^{*}$ \\
\hline Marriage & 0.060 & 0.021 & 0.012 & 0.063 & 0.060 & 0.059 \\
\hline Education & $0.098 * *$ & -0.028 & $0.063 *$ & $0.094 *$ & $0.101 * *$ & $0.095 * *$ \\
\hline Tenure & 0.050 & -0.057 & -0.071 & 0.041 & 0.046 & 0.057 \\
\hline Employment Type & -0.029 & 0.051 & 0.079 * & -0.021 & -0.025 & -0.022 \\
\hline Workplace safety climate & -0.057 * & $0.078 *$ & 0.071 * & -0.045 & $-0.053 *$ & \\
\hline Affect-based Trust & & & & $-0.155^{* * *}$ & & $-0.156^{* * *}$ \\
\hline Cognition-based Trust & & & & & -0.054 * & 0.004 \\
\hline $\mathrm{R}^{2}$ & 0.026 & 0.019 & 0.050 & 0.050 & 0.029 & 0.049 \\
\hline $\mathrm{F}$ & $3.850 * * *$ & $2.724^{* *}$ & $7.551^{* * *}$ & $6.524^{* * *}$ & $3.732 * * *$ & $6.520^{* * *}$ \\
\hline DW & 2.044 & 1.913 & 2.078 & 2.053 & 2.043 & 2.052 \\
\hline
\end{tabular}

Note: ${ }^{*} p<0.10,{ }^{* *} p<0.01,{ }^{* * *} p<0.05$. DW $=$ Durbin-Watson

Direct effect of WSC. As shown in Table 3, the results of Model 1 showed that WSC exerts a significant negative effect on presenteeism $(\beta=-0.057, p<0.05)$, which supported H1.

Mediating effects of affect-based trust and cognition-based trust. Regarding the mediator of affect-based trust, as shown in Table 3, the results of Model 1 indicate that WSC has a significant 
negative effect on presenteeism $(\beta=-0.057, p<0.05)$. The results of Model 2 show that WSC has a significant positive effect on affect-based trust $(\beta=0.078, p<0.05)$, supporting H2a. The results of Model 4 show that affect-based trust exerts a significant negative effect on presenteeism $(\beta=-0.155$, $p<0.001)$. When affect-based trust has been introduced as mediator, the effect of WSC on presenteeism became insignificant $(\beta=-0.045, p>0.05$ ). This shows that affect-based trust plays a complete mediating role between WSC and presenteeism. Thus, H3a was supported.

With regard to the mediator of cognition-based trust, as shown in Table 3, the results of Model 1 indicate that WSC has a significant negative effect on presenteeism $(\beta=-0.057, p<0.05)$. The results of Model 3 show that WSC has a significant positive effect on cognition-based trust $(\beta=0.071, p<0.05)$, thus supporting $\mathrm{H} 2 \mathrm{~b}$. The results of Model 5 show that cognition-based trust exerts a significant negative effect on presenteeism $(\beta=-0.154, p<0.05)$. When cognition-based trust has been introduced as mediator, the effect of WSC on presenteeism became significantly smaller $(\beta=-0.053, p<0.05)$ compared with Model 1. This shows that cognition-based trust plays a partial mediating role between WSC and presenteeism. Thus, H3b was supported.

In addition, this study further explored the relationship between affect-based trust and cognition-based trust. As shown in Table 3, the results of Model 6 indicate that when affect-based trust and cognition-based trust were simultaneously controlled, the effect of cognition-based trust on presenteeism became insignificant $(\beta=0.004, p>0.05)$. However, affect-based trust exerted a significant negative effect on presenteeism $(\beta=-0.156, p<0.001)$, indicating that cognition-based trust completely mediates the relationship between affect-based trust and presenteeism. Cognition-based trust must be transformed into affect-based trust to influence presenteeism.

Moderating effect test of organizational formalization. To alleviate the collinearity problem, this study centered variables on WSC and organizational formalization at their means before constructing interaction terms. The names of such mean-centered variables start with "z." The test results are presented in Table 4.

Table 4. Test results of the moderating effect test of organizational formalization.

\begin{tabular}{|c|c|c|c|c|c|c|}
\hline \multirow{2}{*}{ Variable } & \multicolumn{3}{|c|}{ Affect-Based Trust } & \multicolumn{3}{|c|}{ Cognition-Based Trust } \\
\hline & Model 7 & Model 8 & Model 9 & Model 10 & Model 11 & Model 12 \\
\hline Gender & 0.016 & 0.038 & 0.036 & -0.018 & 0.004 & 0.002 \\
\hline Age & $0.131^{* *}$ & 0.078 * & $0.080 *$ & $0.243^{* * *}$ & $0.193^{* * *}$ & $0.194^{* * *}$ \\
\hline Marriage & 0.021 & 0.035 & 0.036 & 0.012 & 0.026 & 0.026 \\
\hline Education & -0.028 & -0.012 & -0.011 & $0.063 *$ & 0.077 * & $0.078^{*}$ \\
\hline Tenure & -0.057 & -0.039 & -0.038 & -0.071 & -0.055 & -0.054 \\
\hline Employment Type & 0.051 & 0.047 & 0.047 & $0.079 *$ & $0.076^{*}$ & $0.076^{*}$ \\
\hline Z Workplace safety climate & $0.078 *$ & 0.068 * & 0.064 * & 0.071 * & 0.061 * & $0.059 *$ \\
\hline Z Organizational formalization & & $-0.258^{* * *}$ & $-0.263^{* * *}$ & & $-0.247^{* * *}$ & $-0.250^{* * *}$ \\
\hline $\begin{array}{l}\text { Z Workplace safety climate * Z } \\
\text { Organizational formalization }\end{array}$ & & & $0.050 *$ & & & 0.031 \\
\hline $\mathrm{R}^{2}$ & 0.019 & 0.083 & 0.095 & 0.050 & 0.109 & 0.110 \\
\hline$\Delta \mathrm{R}^{2}$ & 0.019 & 0.064 & 0.012 & 0.050 & 0.059 & 0.001 \\
\hline $\mathrm{F}$ & $2.724^{* *}$ & $11.264^{* * *}$ & $10.328^{* * *}$ & $7.551^{* * *}$ & $15.273^{* * *}$ & $13.694^{* * *}$ \\
\hline DW & & 1.947 & & & 2.083 & \\
\hline
\end{tabular}

With regard to the moderating effect that organizational formalization exerts on the relationship between WSC and affect-based trust, the results of the three stepwise regression equations of Model 7, Model 8, and Model 9 showed that the interaction term had a significant positive impact on affect-based trust $(\beta=0.050, p<0.05)$. The explanatory power of Model 9 was also significantly enhanced ( $\triangle R^{2}=0.012$, thus obeying the $F$ distribution). In addition, as shown in Figure 2, compared with low organizational formalization, when the organizational formalization was high, WSC had a 
weaker effect on affect-based trust. Therefore, organizational formalization had a negative moderating effect on the relationship between WSC and affect-based trust. Thus, H4a was supported. Similarly, with regard to the moderating effect of organizational formalization on the relationship between WSC and cognition-based trust, the results of three stepwise regression equations of Model 10, Model 11, and Model 12 showed that the influence coefficient of the interaction term on cognition-based trust was not significant. Thus, $\mathrm{H} 4 \mathrm{~b}$ was not supported. It means that organization formalization exerts a positive moderating effect on the relationship between WSC and affect-based trust. However, it exerts no significant moderating effect on the relationship between WSC and cognition-based trust. Affect-based trust forms an emotional link based on sensibility. The existence of a formal organizational structure will enhance the perception of the importance an organization attaches to organizational safety management. Employees assume that the organization will respect and care about their safety and health. Therefore, a formal organizational structure will positively affect the relationship between WSC and emotional trust. However, cognition-based trust is based on rationality and represents the objective feeling of organizational safety management capability. Regardless of how the organizational structure changes, the objective judgment of this basic cognition will remain unaffected. Therefore, organizational formalization exerts no significant moderating effect on the relationship between WSC and cognition-based trust.

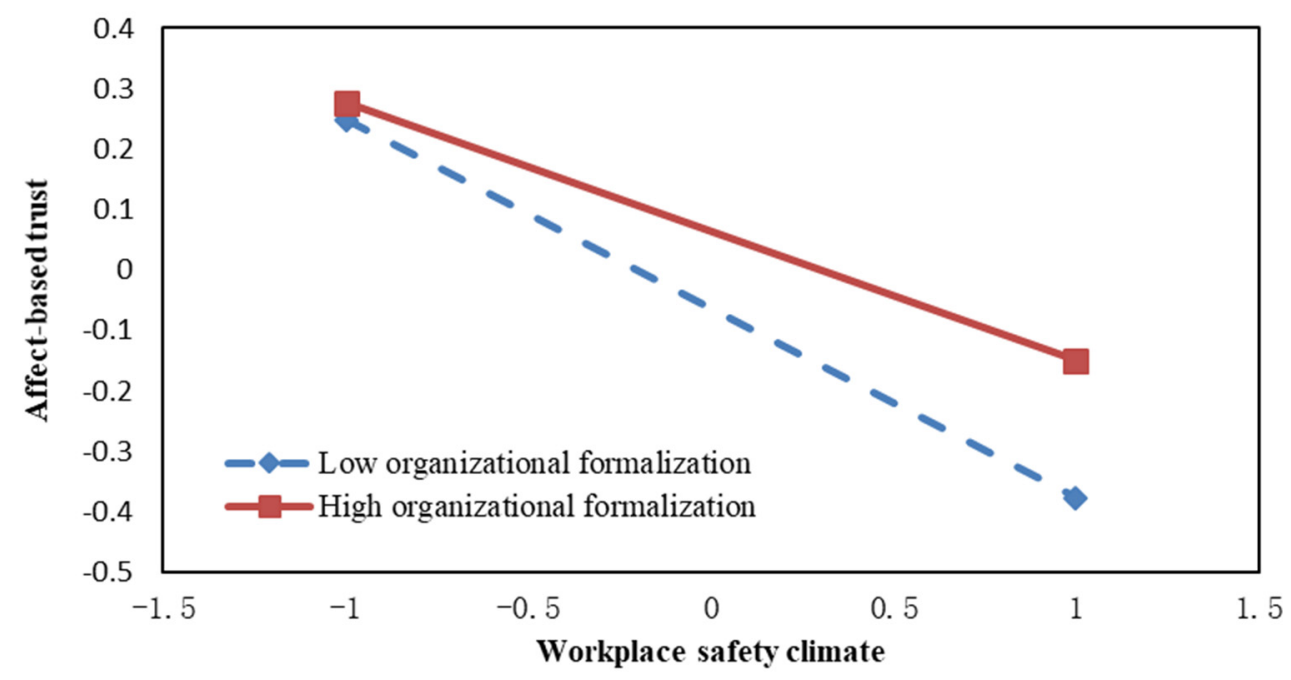

Figure 2. The moderating effect test of organizational formalization.

\section{Discussion}

Previous studies showed that presenteeism could cause more productivity loss to an organization than absence [6,7]. The effective management of presenteeism can improve organizational efficiency. Studies on presenteeism confirmed that job insecurity affects both the work behaviors and decisions of employees [3,5]. However, few studies have explored variables that were less proximal to the workplace such as environmental factors [1]. The existing research only starts from the single perspective of social cognition [26] or social exchange [33], which may not be able to provide a comprehensive explanation on presenteeism. Therefore, according to the SOR theory and CAPS, this study explored the intrinsic mechanism between WSC and presenteeism from the perspective of affect and cognition. In addition, scholars have called for an investigation of presenteeism to identify the process of decision-making by combining organizational, work-related, and person-related factors [1]. To address this call, this study introduces the organizational structure of organization formalization and explores the boundary conditions for the effectiveness of WSC. The results of this study show that WSC significantly reduces presenteeism. Both affect-based trust and cognition-based trust mediate the relationship between WSC and presenteeism. Affect-based trust exerts a complete mediating role, while cognition-based trust exerts a partial mediating role. Cognition-based trust completely mediates the relationship between 
affect-based trust and presenteeism. Organization formalization exerts a positive moderating effect on the relationship between WSC and affect-based trust.

\subsection{Theoretical Implications}

WSC positively reduces presenteeism. First, most research on the antecedents of presenteeism focused on individual resources [25] and working characteristics [5,30]. However, few studies focused on the characteristics of the workplace environment [1]. Moreover, previous studies have focused more on the impact of the environment on subjective job insecurity, e.g., poor economic climate, organizational downsizing, and paid sick leave policy [50]. This study changed the perspective and rather focused on the culture of security created by an objective organizational system. The conclusions of the present study enrich the research results of antecedents of presenteeism to some extent. Second, although existing research has focused on the role of supportive work characteristics toward reducing presenteeism, it mainly focused on the "soft environment," such as leadership support [31] and organizational support [32]. Therefore, scholars have proposed that less proximal workplace factors, such as political, cultural, and regulations, should be explored when studying the impact of presenteeism [1]. This study explored the internal mechanism of the negative relationship between WSC and presenteeism, and to a certain extent, responds to these research appeals of previous scholars. Third, current research on antecedents of presenteeism is mostly theoretical, framework, or literature meta-analysis research $[2,3,5,25,26]$. This study enriches the empirical research of presenteeism in China.

Affect-based trust and cognition-based trust mediate the relationship between WSC and presenteeism. Previous studies tried to explain presenteeism via various theories, e.g., recovery theory [30], "Job Demand-Resource" theory [5,31], stress transactional theory [13], social cognitive theory [26], social information processing theory and resource conservation theory [32], and social exchange theory [33]. There is a lack of a comprehensive framework that takes into account cognitive and affective thrust to explain the "why and how" in the presenteeism context. First, based on the SOR theory, this study constructed a theoretical framework for WSC as an organizational environment stimulus that influences presenteeism by transforming different psychological states of affect and cognition. In doing so, this study opened the "black box" between WSC and presenteeism, identified the internal mechanism of individual complex social behaviors, and enriched the application scope of the theory. Second, existing research preliminarily explored the mechanism of WSC, such as safety motivation [18], safety behavior [16], and safety management practice [51]. In contrast to previous studies, this study combined the viewpoints of the CAPS theory and identified both affect-based trust and cognition-based trust as important internal mechanisms with which WSC influences the presenteeism decision-making process. The results enrich the mechanism of WSC and expand the interpretation scope of the CAPS theory. Third, this study further explored that cognition-based trust had to be transformed into affect-based trust to reduce presenteeism. It provides empirical evidence for the argument that cognition precedes affect [52]. This is consistent with previous research conclusions. Cognition-based trust forms the foundation of affect-based trust. Cognition-based trust has a significant positive impact on affect-based trust [53] and cognition-based trust will eventually affect the results through affect-based trust [54].

Organizational formalization is a situational factor to improve the effectiveness of WSC. First, previous literature had suggested that the effectiveness of administrative control was highly dependent on the organizational structure [23]. The present study follows this possibility and revealed that organizational formalization is one of the boundary conditions under which WSC can be more effective. Second, this study helped to clarify the positive effect of organizational formalization to some extent. Organizational formalization creates a good organizational environment for the transmission of WSC. A formalized structure reduces the uncertainty within the transmission of safety management regulations, policies, and procedures, and promotes a consensus of safety management values. Third, this study integrated organizational, work-related, and person-related factors into a research framework, 
thus responding to the research appeal of previous scholars [1]. This integration provided research experience toward a more comprehensive view of the presenteeism decision-making process.

\subsection{Managerial Implications}

The effective management of presenteeism helps to reduce risks related to human resources and promotes the sustainable development of an organization. Not only the organizational situation, but also different cognitive and affective driving forces, will affect the presenteeism decision-making process. The conclusion has the following practical significance for organization managers:

Managers need to devote themselves to creating a positive WSC to reduce presenteeism. Sustainable psychology emphasizes the importance of creating a sustainable organizational environment that promotes employee health and well-being [14]. The empirical result showed that WSC significantly reduces presenteeism. Therefore, managers need to devote themselves to creating a positive WSC.

WSC refers to safety management priorities, systems, practices, and procedures to reward, support, and persuade employees to behave safely [15]. First, the organization should create a safety culture, take safety management measures, emphasize safety practices, and convey to its employees that safety management takes priority over production targets. Second, managers should encourage employees to participate in safety activities and observe safe work conventions [34]. Managers need to clarify both safety rules and policies and provide regular safety training and education. When necessary, managers should put safety behaviors and safety outcomes into their performance appraisal system. Third, an organization regulates safety behavior by creating a safety culture and by sharing safety awareness [35], thus promoting safe compliance and safe participation, reducing presenteeism, and improving the safety performance of the organization.

Build an atmosphere that promotes affect-based trust and cognition-based trust to reduce presenteeism. First, affect-based trust originates from the development of emotional relationships. A deep and stable social relationship forms during the process of reciprocal social exchange [38]. Therefore, managers should listen to employees and adopt their opinions about safety and health. This will strengthen both mutual communication and affective support between the organization and employees. Through actively fulfilling the normative commitment to health and safety, an organization can have high-quality social exchange with its employees and increase their affect-based trust. Second, cognition-based trust depends on the reasonable and objective evaluation of the characteristics of others or organizations, including their capability and reliability [39]. Therefore, managers should commit to improve both the safety and stability of the organization. To increase the level of safety participation, employee safety participation should be increased through consultation with trade unions, occupational safety representatives, and by other means. Managers should provide guidance, help, and support for employees' safety and health, and provide timely functional help when employees are ill. This will stimulate cognition-based trust in the safety management capability of the organization. Third, cognition-based trust has a significant positive impact on affect-based trust [53], and cognition-based trust will eventually affect the results through affect-based trust [54]. Affect-based trust forms the link to cognition-based trust transformation. Therefore, organizations should build, cultivate, and promote affect-based trust with employees through multiple channels. These can be helping employees balance their health and performance goals, caring for employees' well-being, interacting with employees on safety issues, as well as consciously influencing employees and enabling them to trust the supportive management activities of the organization.

Promoting the effect of safety management through a formal organizational structure. Previous studies have shown that formal organizational structure may have a negative impact on the results of organizations or employees, such as reducing organizational performance and increasing anti-production behavior [43,55]. This study helped to clarify the positive effect of organizational formalization. Organizational formalization is one of the boundary conditions under which WSC can be more effective. It can effectively promote the influence of WSC on affect-based trust, which completely mediates the relationship between affect-based trust and presenteeism. Therefore, organizations need 
to strive to build a formalized organizational structure to create a sustainable workplace environment. First, the organization should prioritize safety and health over production targets by formulating numbers of clear and explicit regulations, thus providing an institutional guarantee for the WSC to promote affect-based trust. Second, the organization should issue official documents, systems, and procedures to send signals that the organization is willing to help and support healthy behaviors. A large number of clear rules and regulations should be formulated to build a consensus on the priority of employee safety and health. Third, efforts should be directed toward constructing stable and predictable safeguard measures to display the intention to focus on the safety and health of employees, through the formal organizational structure to reduce the uncertainty faced by employees during illness and lessen the worries of employees who are absent from work due to illness.

\subsection{Limitations and Future Research}

Like all studies, this research had a number of limitations. First, this study used healthcare employees as a sample group. Although this can effectively control the influence of factors, such as work characteristics, and improve the internal validity of the study, it also limits the possibility that the results can be inferred to other types of organizations. Future research should expand the sample source, verify the research conclusions in a wider sample range, and improve the universality of the presented research. Second, this study showed that cognition-based trust is not the only mediating variable between WSC and presenteeism, and there are other complementary mediating variables. Future studies should introduce other mediation variables to enrich the research model, and to further expand the research on the internal mechanism with which WSC reduces presenteeism. Third, scholars have suggested that presenteeism may also have positive effects in balancing work performance and physical health [25]. Future research should focus on functional presenteeism and provide empirical evidence as well as practical information for sustainable human resources management.

Author Contributions: Conceptualization, B.L., and Q.L.; data curation and methodology, Q.L.; writing—original draft, B.L., and Q.L.; writing-review and editing, B.L. and Q.L.; project administration B.L.; funding acquisition, B.L., and Q.L. All authors have read and agreed to the published version of the manuscript.

Funding: This research was funded by Humanities and Social Science Fund of Ministry of Education of China, grant number 19YJC790077. Social Science Program of Beijing Municipal Education Commission, grant number SM202010011005. Young Teachers' Scientific Research Start-up Fund, grand number PXM2019_014213_000007.

Conflicts of Interest: The authors declare no conflict of interest.

\section{References}

1. Lohaus, D.; Habermann, W. Presenteeism: A review and research directions. Hum. Resour. Manag. R. 2019, 29, 43-58. [CrossRef]

2. Halbesleben, J.R.B.; Whitman, M.V.; Crawford, W.S. A dialectical theory of the decision to go to work: Bringing together absenteeism and presenteeism. Hum. Resour. Manag. R. 2014, 24, 177-192. [CrossRef]

3. Johns, G. Presenteeism in the workplace: A review and research agenda. J. Organ. Behav. 2010, 31, 519-542. [CrossRef]

4. Aronsson, G.; Gustafsson, K.; Dallner, M. Sick but yet at work. An empirical study of sickness presenteeism. J. Epidemiol. Commun. Health 2000, 54, 502-509. [CrossRef] [PubMed]

5. Miraglia, M.; Johns, G. Going to work ill: A meta-Analysis of the correlates of presenteeism and a dual-Path model. J. Occup. Health Psych. 2016, 21, 261-283. [CrossRef] [PubMed]

6. Evans-Lacko, S.; Knapp, M. Global patterns of workplace productivity for people with depression: Absenteeism and presenteeism costs across eight diverse countries. Soc. Psych. Psych. Epid. 2016, 51, 1525-1537. [CrossRef]

7. Hemp, P. Presenteeism: At work-But out of it. Harv. Bus. Rev. 2004, 82, 49-58. [PubMed]

8. Becker, K.; Smidt, M. A risk perspective on human resource management: A review and directions for future research. Hum. Resour. Manag. R. 2016, 26, 149-165. [CrossRef] 
9. Saridakis, G.; Lai, Y.; Cooper, C.L. Exploring the relationship between HRM and firm performance: A meta-Analysis of longitudinal studies. Hum. Resour. Manag. R. 2017, 27, 87-96. [CrossRef]

10. Pohling, R.; Buruck, G.; Jungbauer, K.; Leiter, M.P. Work-Related factors of presenteeism: The mediating role of mental and physical health. J. Occup. Health Psych. 2016, 21, 220-234. [CrossRef]

11. Lu, L.; Cooper, C.L.; Lin, H.Y. A cross-Cultural examination of presenteeism and supervisory support. Career Dev. Int. 2013, 18, 440-456. [CrossRef]

12. Lu, K.M.; Pan, S.Y.; Cheng, J.W. Examination of a perceived cost model of employees' negative feedback-Seeking behavior. J. Psychol. 2011, 145, 573-594. [CrossRef] [PubMed]

13. Lu, L.; Lin, H.Y.; Cooper, C.L. Unhealthy and present: Motives and consequences of the act of presenteeism among Taiwanese employees. J. Occup. Health Psych. 2013, 18, 406-416. [CrossRef]

14. Vila-Vázquez, G.; Castro-Casal, C.; Álvarez-Pérez, D.; del Río-Araújo, L. Promoting the Sustainability of Organizations: Contribution of Transformational Leadership to Job Engagement. Sustainability 2018, 10, 4109. [CrossRef]

15. Zohar, D. Safety climate: Conceptual and measurement issues. In Handbook of Occupational Health Psychology; Quick, J.C., Tetrick, L.E., Eds.; American Psychological Association: Washington, DC, USA, 2003; pp. 123-142.

16. Beus, J.M.; Payne, S.C.; Bergman, M.E.; Arthur, W. Safety climate and injuries: An examination of theoretical and empirical relationships. J. Appl. Psychol. 2010, 95, 713-727. [CrossRef] [PubMed]

17. Curcuruto, M.; Griffin, M.A.; Kandola, R.; Morgan, J.I. Multilevel safety climate in the UK rail industry: A cross validation of the Zohar and Luria MSC scale. Saf. Sci. 2018, 110, 183-194. [CrossRef]

18. Neal, A.; Griffin, M.A. A study of the lagged relationships among safety climate, safety motivation, safety behavior, and accidents at the individual and group levels. J. Appl. Psychol. 2006, 91, 946-953. [CrossRef]

19. Namkung, Y.; Jang, S.C. Effects of perceived service fairness on emotions, and behavioral intentions in restaurants. Eur. J. Mark. 2010, 44, 1233-1259. [CrossRef]

20. Jacoby, J. Stimulus-Organism-Response reconsidered: An evolutionary step in modeling (Consumer) Behavior. J. Consum. Psychol. 2002, 12, 51-57. [CrossRef]

21. Das, T.K.; Teng, B.S. Between trust and control: Developing confidence in partner cooperation in alliances. Acad. Manag. Rev. 1998, 23, 491-512. [CrossRef]

22. McAllister, D.J. Affect- and cognition-Based trust as foundations for interpersonal cooperation in organizations. Acad. Manag. J. 1995, 38, 24-59.

23. Ambrose, M.L.; Schminke, M. Organization structure as a moderator of the relationship between procedural justice, interactional justice, perceived organizational support, and supervisory trust. J. Appl. Psychol. 2003, 88, 295-305. [CrossRef] [PubMed]

24. Mischel, W.; Shoda, Y. Reconciling processing dynamics and personality dispositions. Annu. Rev. Psychol. 1998, 49, 229-258. [CrossRef] [PubMed]

25. Karanika-Murray, M.; Biron, C. The health-Performance framework of presenteeism: Towards understanding an adaptive behavior. Hum. Relat. 2020, 73, 242-261. [CrossRef]

26. Cooper, C.L.; Lu, L. Presenteeism as a global phenomenon: Unraveling the psychosocial mechanisms from the perspective of social cognitive theory. Cross Cult. Strateg. M. 2016, 23, 216-231. [CrossRef]

27. Zhang, W.; Sun, H.; Woodcock, S.; Anis, A. Illness related wage and productivity losses: Valuing 'presenteeism'. Soc. Sci. Med. 2015, 147, 62-71. [CrossRef] [PubMed]

28. Goetzel, R.Z.; Carls, G.S.; Wang, S.; Kelly, E.; Mauceri, E.; Columbus, D.; Cavuoti, A. The relationship between modifiable health risk factors and medical expenditures, absenteeism, short-Term disability, and presenteeism among employees at Novartis. J. Occup. Environ. Med. 2009, 51, 487-499. [CrossRef] [PubMed]

29. Wang, Y.; Chen, C.C.; Lu, L.; Eisenberger, R.; Fosh, P. Effects of leader-Member exchange and workload on presenteeism. J. Manag. Psychol. 2018, 33, 511-523. [CrossRef]

30. Meijman, T.F.; Mulder, G. Psychological aspects of workload. In Handbook of Work and Organizational Psychology, 2nd ed.; Drenth, P.J., Thierry, H., de Wolff, C.J., Eds.; Taylor \& Francis: Hove, UK, 1998; pp. 5-33.

31. Glazer, S.; Kozusznik, M.W.; Meyers, J.H.; Ganai, O. Meaningfulness as a resource to mitigate work stress. In Contemporary Occupational Health Psychology: Global Perspectives on Research and Practice; Leka, S., Sinclair, R.R., Eds.; Wiley-Blackwell: Chichester, UK, 2014; pp. 114-130.

32. Zhou, Q.; Martinez, L.F.; Ferreira, A.I.; Rodrigues, P. Supervisor support, role ambiguity and productivity associated with presenteeism: A longitudinal study. J. Bus. Res. 2016, 69, 3380-3387. [CrossRef] 
33. Haque, A.; Fernando, M.; Caputi, P. Perceived human resource management and presenteeism: Mediating effect of turnover intentions. Asia-Pac. J. Bus. Adm. 2019, 11, 110-130. [CrossRef]

34. Nahrgang, J.D.; Morgeson, F.P.; Hofmann, D.A. Safety at work: A meta-Analytic investigation of the link between job demands, job resources, burnout, engagement, and safety outcomes. J. Appl. Psychol. 2011, 96, 71-94. [CrossRef] [PubMed]

35. Martínez-Córcoles, M.; Gracia, F.; Tomás, I.; Peiró, J.M. Leadership and Employees' Perceived Safety Behaviors in a Nuclear Power Plant: A Structural Equation Model. Safety Sci. 2011, 49, 1118-1129. [CrossRef]

36. Xu, X.; Le, N.; He, Y.; Yao, X. Team Conscientiousness, Team Safety Climate, and Individual Safety Performance: A Cross-Level Mediation Model. J. Bus. Psychol. 2019, 6, 1-20. [CrossRef]

37. Christian, M.S.; Bradley, J.C.; Wallace, J.C.; Burke, M.J. Workplace safety: A meta-Analysis of the roles of person and situation factors. J. Appl. Psychol. 2009, 94, 1103-1127. [CrossRef]

38. Schaubroeck, J.M.; Peng, A.C.; Hannah, S.T. Developing trust with peers and leaders. Acad. Manag. J. 2015, 55, 1148-1168.

39. Wang, S.; Tomlinson, E.C.; Noe, R.A. The role of mentor trust and protégé internal locus of control in formal mentoring relationships. J. Appl. Psychol. 2010, 95, 358-367. [CrossRef]

40. Methot, J.R.; Lepine, J.A.; Podsakoff, N.P.; Siegel, J. Are workplace friendships a mixed blessing? Exploring tradeoffs of multiplex relationships and their associations with job performance. Pers. Psychol. 2016, 69, 311-355. [CrossRef]

41. Dollard, M.F.; Bakker, A.B. Psychosocial safety climate as a precursor to conducive work environments, psychological health problems, and employee engagement. J. Occup. Organ. Psych. 2010, 83, 579-599. [CrossRef]

42. Colquitt, J.A.; Lepine, J.A.; Piccolo, R.F.; Zapata, C.P.; Rich, B.L. Explaining the justice-Performance relationship: Trust as exchange deepener or trust as uncertainty reducer. J. Appl. Psychol. 2012, 97, 1-15. [CrossRef]

43. Pugh, D.S.; Hickson, D.J.; Turner, C.R.H. Dimensions of organization structure. Admin. Sci. Quart. 1968, 13, 65-105. [CrossRef]

44. Aryee, S.; Sun, L.Y.; Chen, Z.X.G.; Debrah, Y.A. Abusive supervision and contextual performance: The mediating role of emotional exhaustion and the moderating role of work unit structure. Manag. Organ. Rev. 2008, 4, 393-411. [CrossRef]

45. Hempel, P.S.; Zhang, Z.X.; Han, Y.L. Team empowerment, the organizational context decentralization, and the contrasting effects of formalization. J. Manag. 2012, 38, 476-501.

46. Heponiemi, T.; Elovainio, M.; Pentti, J.; Virtanen, M.; Vahtera, J. Association of contractual and subjective job insecurity with sickness presenteeism among public sector employees. J. Occup. Environ. Med. 2010, 52, 830-835. [CrossRef] [PubMed]

47. Podsako, P.M.; MacKenzie, S.B.; Lee, J.Y.; Podsako, N.P. Common method biases in behavioral research: A critical review of the literature and recommended remedies. J. Appl. Psychol. 2003, 88, 879-903. [CrossRef] [PubMed]

48. Johnson, R.E.; Rosen, C.C.; Djurdjevic, E. Assessing the impact of common method variance on higher order multidimensional constructs. J. Appl. Psychol. 2011, 96, 744-761. [CrossRef] [PubMed]

49. Nunnally, J. Psychometric Theory: Measurement in Science, 2nd ed.; McGraw-Hill: New York, NY, USA, 1978; pp. 3-24.

50. De Paola, M.; Scoppa, V.; Pupo, V. Absenteeism in the Italian public sector: The effects of changes in sick leave policy. J. Labor Econ. 2014, 32, 337-360. [CrossRef]

51. Custo, P.T.; Custo, R.T.; Buttigieg, S. The Relationship between Safety Climate and Performance in Intensive Care Units: The Mediating Role of Managerial Safety Practices and Priority of Safety. Front. Public Health 2019, 7, 302. [CrossRef] [PubMed]

52. Lazarus, R.S. Thoughts on the relations between emotion and cognition. Am. Psychol. 1982, 37, $1019-1024$. [CrossRef]

53. Johnson, D.; Grayson, K. Cognitive and affective trust in service relationships. J. Bus. Res. 2005, 58, 500-507. [CrossRef] 
54. Jarratt, D.; Ceric, A. The complexity of trust in business collaborations. Australas. Mark. J. 2015, $23,2-12$. [CrossRef]

55. Sundaramurthy, C.; Lewis, M. Control and collaboration: Paradoxes of governance. Acad. Manag. Rev. 2003, 28, 397-415. [CrossRef] 